\title{
Electrical Responses of the Smooth Muscle of the Guinea-pig Cerebral Artery to Brief Electrical Stimulation
}

\author{
Yoshimichi Yamamoto and Ken Hotta \\ Department of Physiology, Nagoya City University Medical School, \\ Mizuho-ku, Nagoya, 467 Japan
}

\begin{abstract}
Electrical responses to brief electrical stimulation were investigated in the cerebral artery of a guinea-pig using a microelectrode. A single brief stimulus $(0.05 \mathrm{~ms})$ induced a spike potential followed by a depolarizing slow-potential, and these events were associated with muscle contraction. An outward current injected into the smooth muscle cell induced spike potential but failed to induce depolarizing slow-potential. These activities persisted in the presence of TTX $\left(10^{-6} \mathrm{M}\right)$, guanethidine $\left(5 \times 10^{-6} \mathrm{M}\right)$, or atropin $\left(10^{-5} \mathrm{M}\right)$. TEA $(5 \mathrm{mM})$ enhanced the amplitude of the spike potential, but not that of the depolarizing slow-potential. When the external $\mathrm{Na}$ was reduced, the membrane transiently hyperpolarized. During this period, the depolarizing slow-potential could be evoked. In a Cl-deficient solution, the membrane depolarized and the amplitude of the depolarizing slow-potential decreased. From these observations it is believed that the contribution of $\mathrm{K}, \mathrm{Na}$, or $\mathrm{Cl}$ is minor. In a $20 \mathrm{mM}-\mathrm{Ca}$ solution, a brief stimulation induced neither spike potential nor depolarizing slow-potential, but did induce a hyperpolarizing slow-potential. The hyperpolarizing slow-potential was also induced in a Na-deficient solution, but only after completion of $\mathrm{Na}$ re-distribution across the membrane. These observations suggest that a substance released by brief stimulation produces a prolonged change in ionic conductances of the smooth muscle membrane, allowing the muscle to contract for a certain period.
\end{abstract}

Key words: spike potential, electrical stimulation, guinea-pig cerebral artery, slow potential, smooth muscle.

Cerebral blood vessels of several species, including the guinea-pig, are innervated by both sympathetic and parasympathetic nerves (see review of EDVINSSON and MackenZIE, 1976). And perivascular nerve stimulation evoked excitatory junction potential (e.j.p.) in the guinea-pig basilar artery (KARASHIMA and

Received for publication September 12, 1985 
Kuriyama, 1981). The amplitude of e.j.p., however, was very small and a spike potential was induced only by repeptitive high frequency stimulation and in the presence of TEA. On the other hand, HIRST et al. (1982) reported a regenerative spike potential associated with vasoconstriction evoked in the rat basilar artery, by a single brief stimulation, in the absence of TEA. As the role of the neural mechanism in controlling the cerebral blood flow is controversial (HEISTAD and Marcus, 1978; Purves, 1978), the discrepancy between these results has to be examined.

In a dog's middle cerebral artery, SuzUKI and FuJIWARA (1982) reported that the perivascular nerve stimulation induced a slow hyperpolarization which was not blocked by either 6-hydroxy-dopamine nor by atropine. This suggests that a dog's cerebral artery possesses a functioning nonadrenergic, noncholinergic inhibitory nerve. It shall be interesting to see whether this inhibitory system is special to the cerebral artery of a dog or is inherent in the cerebral artery of other species.

The present study was undertaken in order to investigate the mechanism underlying electrical activities induced by brief electrical stimulation. Our observations suggest that a substance released by brief stimulation produces prolonged change in ionic conductances of the smooth muscle membrane, allowing the muscle to contract for a certain period. This artery generates a hyperpolarizing potential as was observed in the dog's cerebral artery (SUZUKI and FujIWARA, 1982).

\section{MATERIALS AND METHODS}

Female guinea-pigs weighing about $300 \mathrm{~g}$ were decapitated, and the brain was soaked in an aerated Krebs solution. Under a binocular microscope, bilateral parts of the circle of Willis consisting of the posterior cerebral arteries and the posterior communicating arteries were excised. In some experiments, the basilar artery was also excised. The diameters of the arteries of the circle of Willis were between 0.1 and $0.2 \mathrm{~mm}$, and that of the basilar artery was between 0.2 and $0.3 \mathrm{~mm}$. These arteries were left intact (no further dissection) and pinned at both cut ends to a silicone rubber block placed in a perfusion chamber. Measurements were begun only after a stabilizing period of at least $60 \mathrm{~min}$.

The volume of the perfusion chamber was about $0.75 \mathrm{ml}$ and the flow rate of the perfusate was $3 \mathrm{ml} / \mathrm{min}$ (perfusion pump). The temperature of the perfusate was maintained at $35^{\circ} \mathrm{C}$ throughout the experiment.

A large part of the present study was performed with the apparatus shown in Fig. 1 A. Electrical stimulation was applied to the tissue, using a modified pointstimulating method originally described by SuzuKi and FuJiwara (1982). The cathodal electrode was a platinum plate placed in the chamber. The anodal electrode was a platinum wire $0.2 \mathrm{~mm}$ in diameter, and was coated with enamel apart from its cut end which was brought into slight contact with the surface of the artery. The polarity of the stimulus mentioned above was determined in order to minimize the stimulus artifact on the potential recording, because no qualitative difference 
A

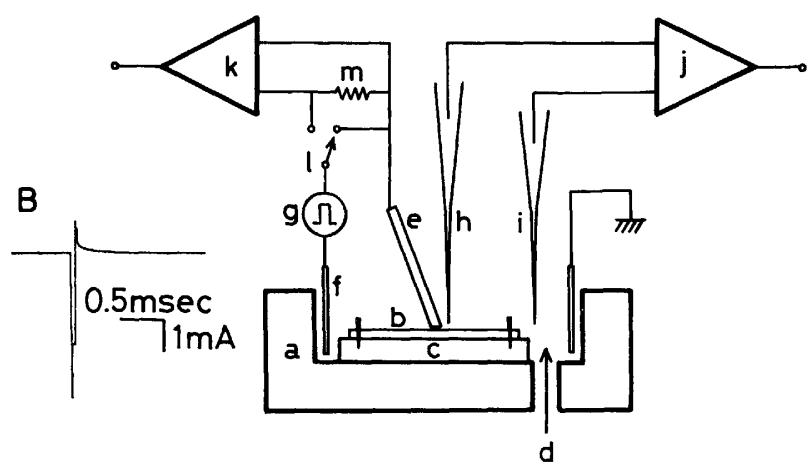

Fig. 1. A: schematic illustration of the experimental apparatus. a, perfusion chamber; b, specimen (artery); c, silicone rubber block; d, inlet of perfusate (overflowed perfusate was removed by suction); e, anodal stimulating electrode; f, cathodal stimulating electrode; $g$, stimulator with isolator; $h$ and $i$ microelectrodes; $j$ and $k$, differential pre-amplifiers for microelectrodes; 1, switch for measurement of current; m: resistor of $100 \Omega$. B: recording of actual stimulating current. An error caused by insertion of resistor $(\mathrm{m}, 100 \Omega)$ into the circuit was less than $10 \%$, because the resistance between two stimulating electrodes (e and f) was more than $1 \mathrm{k} \Omega$ in the Krebs solution.

was observed by changing the polarity. In some experiments, the bare surface of the stimulating electrodes was coated with black platinum to prevent possible polarization of the electrode. However, coating the electrodes made no difference in the results. A single current pulse $0.05 \mathrm{~ms}$ in duration was supplied from an electric stimulator (Nihon Kohden SEN-3201) through an isolator (Nihon Kohden SS102J). Repetitive high frequency stimulation was not given in this experiment. Intensity of the stimulus was expressed as the amplitude of the output voltage of the isolator. The actual stimulating current was also monitored to check the duration of the stimulus. Figure 1B is an example of stimulating current, in which all events ceased within $0.5 \mathrm{~ms}$, although a small positive deflection was observed after the negative square current.

In some experiments, the partition-stimulating method (ABE and TOMITA, 1969) was used to record electrotonic potentials induced by current injection into the smooth muscle cell.

For observation of the membrane activity, a conventional microelectrode filled with $3 \mathrm{M}-\mathrm{KCl}$ with a tip resistance of $40-100 \mathrm{~m} \Omega$ was used. This electrode was impaled from the outer surface of the specimen to within about $0.1 \mathrm{~mm}$ distance from the anodal stimulating electrode. The membrane potential was observed with a pre-amplifier (Nihon Kohden MEZ-7101) as the potential difference between two microelectrodes; one was impaled in the cell and the other placed in the extracellular medium. The potential was recorded on magnetic tape using a data recorder (Sony FE-3507W). Measured membrane potential was expressed as the mean value \pm the 
standard deviation.

When isometric tension was observed, a ring preparation $0.5 \mathrm{~mm}$ in width was dissected from the artery, cut open, placed in the perfusion chamber and fixed vertically between a silicone rubber block and a lever of an isometric force transducer to detect the force developed by the circular muscles. The same anodal stimulating electrode described above was placed close to the outer surface of the artery, and a current pulse $0.05 \mathrm{~ms}$ in duration was applied.

A modified Krebs solution of the following composition was used as the standard perfusate (concentrations in $\mathrm{mM}$ ): $\mathrm{NaCl}, 120.7 ; \mathrm{KCl}, 5.9 ; \mathrm{MgCl}_{2}, 1.2$; $\mathrm{CaCl}_{2}, 2.5 ; \mathrm{NaH}_{2} \mathrm{PO}_{4}, 1.2 ; \mathrm{NaHCO}_{3}, 15.5 ;$ glucose, 11.5. The solution was gassed with $95 \% \mathrm{O}_{2}$ and $5 \% \mathrm{CO}_{2}$, and had a $\mathrm{pH}$ of $7.2-7.3$ at $35^{\circ} \mathrm{C}$. A Na- or Cl-deficient solution was prepared by totally replacing $\mathrm{NaCl}$ with choline chloride or sodium benzenesulfonate, respectively. When tetraethylammonium chloride (TEA) was added, equimolar $\mathrm{NaCl}$ was omitted. In the experiments using a high concentration of $\mathrm{Ca}$, a Tris-buffered solution was used as the standard perfusate instead of a Krebs solution and was of the following composition (mM): $\mathrm{NaCl}, 120.7 ; \mathrm{KCl}, 5.9 ; \mathrm{MgCl}_{2}$, $1.2 ; \mathrm{CaCl}_{2}, 2.5$; Tris, 16.7; glucose, 11.5. The solution was gassed with $100 \% \mathrm{O}_{2}$ and the $\mathrm{pH}$ was adjusted to $7.2-7.3$ at $35^{\circ} \mathrm{C}$ with $\mathrm{HCl}$. To prepare a 10 or $20 \mathrm{~mm}$-Ca solution, the concentration of $\mathrm{CaCl}_{2}$ was raised to 10 or $20 \mathrm{~mm}$ and that of $\mathrm{NaCl}$ was reduced to 109.5 or $94.5 \mathrm{mM}$, respectively (isotonic).

The following drugs were used: tetrodotoxin (TTX, Sankyo), guanethidine sulfate (Tokyo Kasei), and atropine sulfate (Sigma).

\section{RESULTS}

\section{Membrane responses to a brief electrical stimulation}

Most of the present experiments were performed using the arteries of the circle of Willis as the specimen, referred to hereafter as the cerebral artery. The membrane of the smooth muscle cells of the guinea-pig's cerebral artery was electrically quiescent, and neither spontaneous action potential nor miniature excitatory junction potential was observed. The resting membrane potential measured in the Krebs solution varied from cell to cell and from specimen to specimen within the range of -46.2 and $-75.1 \mathrm{mV}$. The mean of the resting membrane potential was $-58.1 \pm 6.8 \mathrm{mV}(n=229)$.

A brief electrical stimulus applied by the point-stimulating method induced the membrane activity, typical examples of which are shown in Fig. 2A, a. A small depolarization of the membrane was induced by a stimulus as low as $1.6 \mathrm{~V}$ in intensity. When the stimulus intensity was increased up to $2.4 \mathrm{~V}$, the depolarization was enlarged and prolonged but a spike potential was not induced (Fig. 2A, b). With stimuli stronger than $2.8 \mathrm{~V}$, regenerative spike potentials were induced (prominently shown in Fig. 2A, c), and were followed by slowly-declining depolarizations (termed depolarizing slow-potential). When the stimulus intensity was raised to $4 \mathrm{~V}$ or more, the peak amplitudes of both the spike potentials and the 

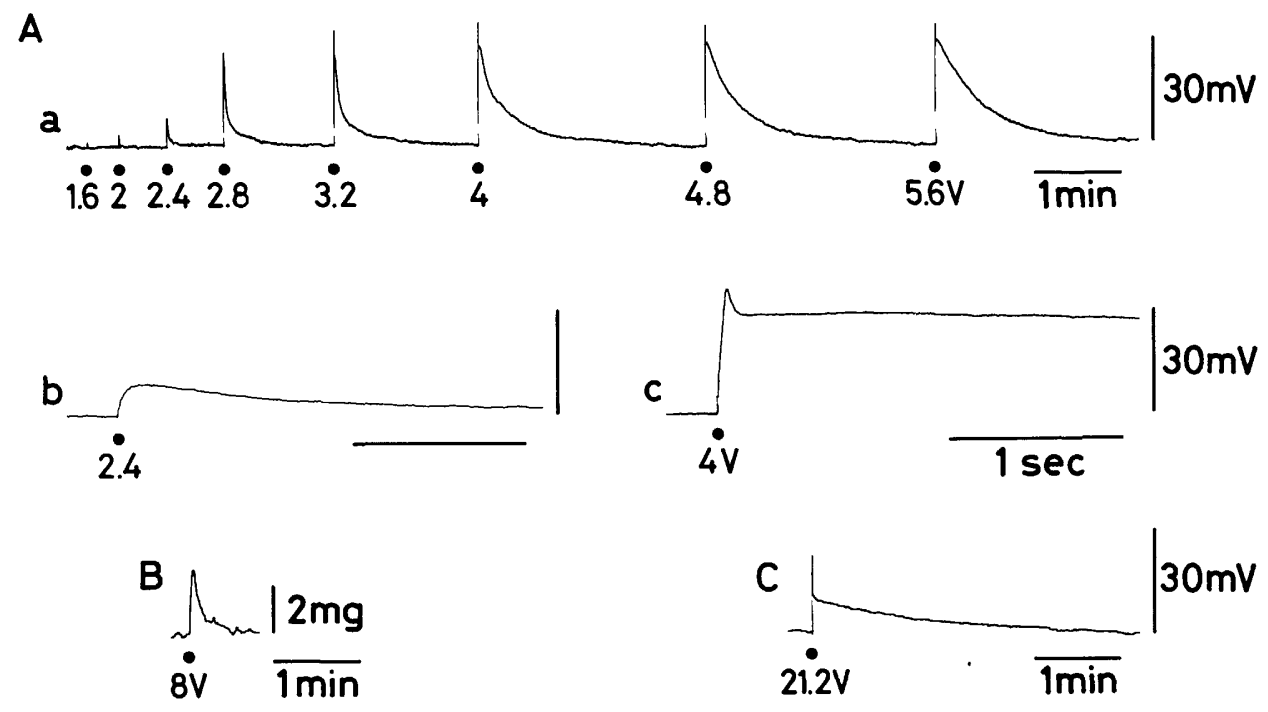

Fig. 2. Typical recordings of electrical and mechanical activities induced by the brief electrical stimulation. In all figures in this paper, the application of the brief electrical stimulation is indicated by a $\operatorname{dot}(\cdot)$ with its intensity under each trace. A: electrical activities recorded in the artery of the circle of Willis. a, slow-sweep recording; $b$ and $c$, fast-sweep recordings of the activities induced by the stimulation of 2.4 and $4.0 \mathrm{~V}$, respectively. B: isometric tension recorded in the artery of the circle of Willis. C: electrical activities recorded in the basilar artery.

following slow potentials remained more or less constant, while the duration of the latter became longer with stronger stimulation. When the partition-stimulating method was used instead of the point-stimulating method, very strong stimulation such as $100 \mathrm{~V}(0.05 \mathrm{~ms})$ induced only a small slow potential without a spike potential.

When the spike potential was induced, the artery appeared to constrict, as viewed microscopically. A small segment of the artery was, then, prepared and the isometric tension was recorded by the same stimulation applied in the experiment of the electrical recording. As shown in Fig. 2B, a brief stimulus current of $0.05 \mathrm{~ms}$ in duration produced a contraction with a rapid rise and a slow decline, which seemed to correspond with the electrical activities. Because the stimulated portion was very small (the diameter of the anodal stimulating electrode was $0.2 \mathrm{~mm}$ ), the amplitude of the detected tension was only a few $\mathrm{mg}$.

Figure 2C shows the electrical activity of the smooth muscle of the guinea-pig basilar artery induced by the brief stimulation. Although a large stimulation was required to induce the activity, it also consisted of a spike potential and a slow potential, which were qualitatively the same as those of the arteries of the circle of Willis. In the present experiment, we focused on the electrical activities, especially on the slowly-declining components of the smooth muscle of the guinea-pig's 

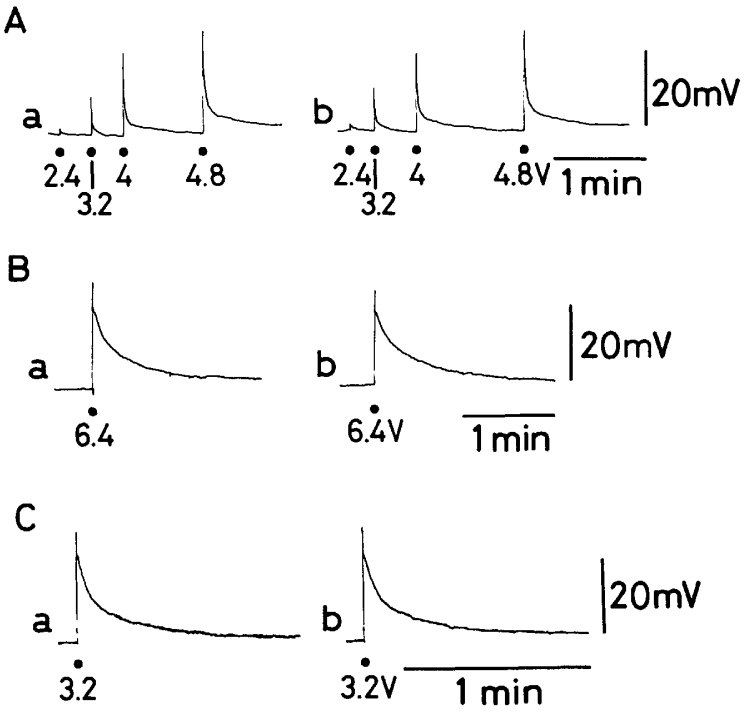

Fig. 3. A: effect of TTX on the electrical activities. Activities in the absence (a) and in the presence (b) of TTX $10^{-6} \mathrm{M}$ for $5 \mathrm{~min}$. B: effect of guanethidine on the electrical activities. Activities in the absence (a) and in the presence (b) of guanethidine $5 \times 10^{-6} \mathrm{M}$ for $1 \mathrm{~h}$. C: effect of atropine on the electrical activities. Activities in the absence (a) and in the presence (b) of atropine $10^{-5} \mathrm{M}$ for $5 \mathrm{~min}$.

cerebral artery as induced by brief electrical stimulation.

\section{Effects of TTX, guanethidine, or atropine on the electrical activities}

As electrical current applied to the artery is assumed to stimulate perivascular nerve fibers, smooth muscle cells, or other cells located in the wall of the artery, the effects of TTX, guanethidine, or atropine on the electrical activities were observed (Fig. 3). If a generation of action potentials in the perivascular nerve fibers is involved in electrical activities induced by brief stimulus current, then TTX would inhibit these activities. In the presence of a high concentration of TTX $\left(10^{-6} \mathrm{M}\right)$, however, the electrical activities of the same amplitude and the same configuration as those in the absence of TTX were induced (Fig. 3A). This does not necessarily mean that the electrical activities were not neurogenic in origin, because the nerve endings or varicosities release transmitters in the presence of TTX, as long as their membrane is depolarized (KATZ and MiLEDI, 1967).

Guanethidine is known to inhibit the release of norepinephrine from the adrenergic fibers. Figure $3 \mathrm{~B}$ shows the effect of guanethidine on electrical activity in the guinea-pig's cerebral artery. Exposure of the specimen to $5 \times 10^{-6} \mathrm{M}$ of guanethidine even for $1 \mathrm{~h}$ failed to block the electrical activities induced by the electrical stimulation. It is unlikely that norepinephrine released from the adrenergic fibers was the main factor related to the electrical activities. Thus, to examine the 

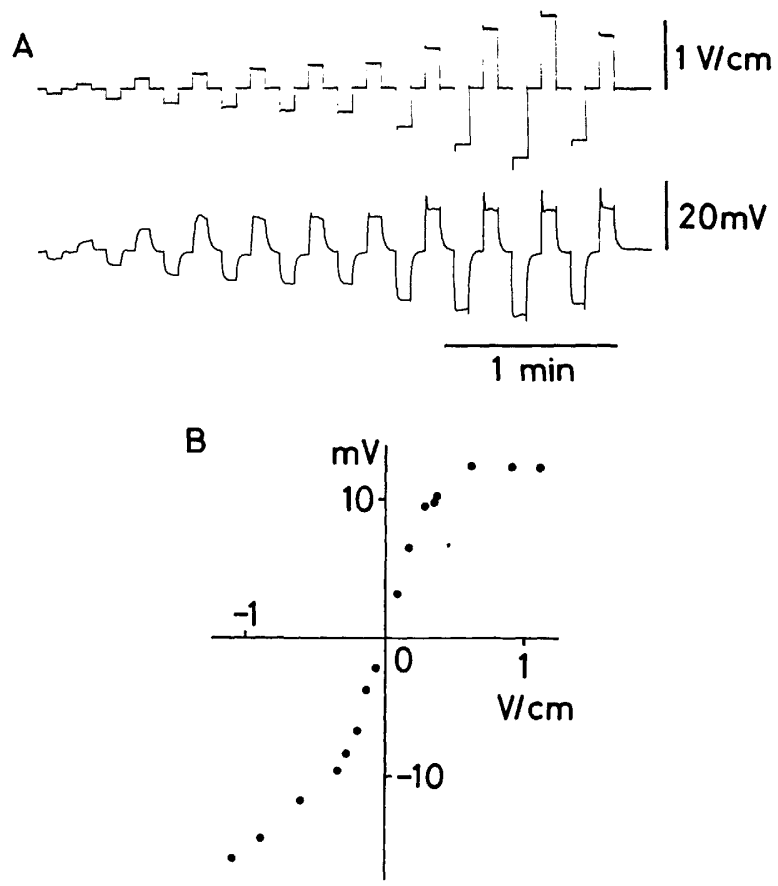

Fig. 4. A: change of the membrane potential induced by current injected into the smooth muscle cell by the partition-stimulating method. The upper trace shows the intensity of injected current (upstroke indicates outward current and downstroke inward current), and the lower trace the membrane potential. B: current-voltage relationship prepared using the intensity of the injected currents and the amplitude of the electrotonic potentials in A.

possible involvement of the cholinergic fibers in the electrical activities, the effect of atropine was observed. High concentrations of atropine $\left(10^{-5} \mathrm{M}\right)$, however, did not modify the electrical activities (Fig. 3C).

\section{Effects of current injection to the smooth muscle cell}

The possibility that electrical activities were induced by direct stimulation to the smooth muscle cells had to be given attention even though a single pulse $0.05 \mathrm{~ms}$ in duration was thought to be far too brief to depolarize these cells directly (PATON, 1975). Figure 4A shows changes in the membrane potential induced by the current injected into the smooth muscle cell by the partition-stimulating method. The duration of each current was $2.5 \mathrm{~s}$, and the membrane potential was recorded about $0.5 \mathrm{~mm}$ apart from the stimulating electrode. Figure 4B shows the current-voltage relationship in which prominent outward and slight inward rectifications are illustrated. As shown in Fig. 4A, the spike potentials were induced by strong outward currents on the beginning of the electrotonic potentials. The membrane, 

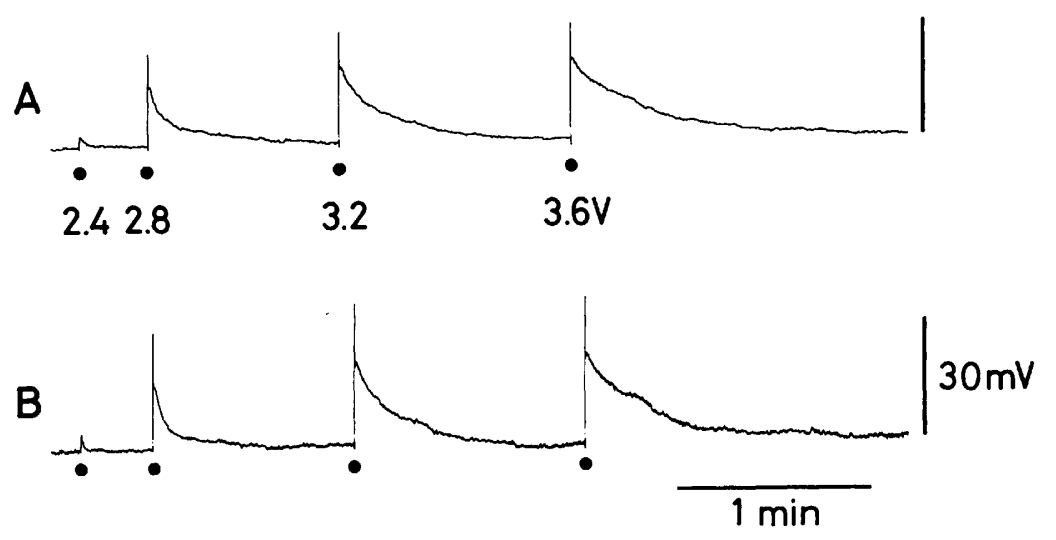

Fig. 5. Effects of TEA on the electrical activities. Activities in the absence (A) and in the presence (B) of TEA $5 \mathrm{~mm}$ for $5 \mathrm{~min}$. The intensity of the stimulations in B was the same as that in A.

however, repolarized rapidly after cessation of the current and a slow potential as that induced by the point-stimulating method was not observed. The electrical activities, or at least their slowly-declining components, did not seem to be induced by direct stimulation to the smooth muscle cells.

\section{Effects of TEA on electrical activities}

TEA reduces the membrane $\mathrm{K}$ conductance in various smooth muscles (HARDER and Sperelakis, 1979; Imaizumi and Watanabe, 1981). To examine the involvement of $\mathrm{K}$ in the slow potential, the effects of TEA on electrical activities were investigated (Fig. 5). In the presence of $5 \mathrm{~mm}$ TEA, the membrane depolarized by a few $\mathrm{mV}$ (in the case of Fig. $5,-63.0 \mathrm{mV}$ in control and $-61.2 \mathrm{mV}$ in TEA), and the amplitude of the spike potentials increased, compared with an absence of the drug. The amplitude and the configuration of the slow potential, however, remained more or less unchanged before and after application of TEA.

\section{Effects of $\mathrm{Na}$ deficiency on electrical activities}

Effects of $\mathrm{Na}$ deficiency on electrical activities were investigated to determine the involvement of $\mathrm{Na}$ in the slow potential (Fig. 6). The effects of $\mathrm{Na}$ deficiency on the nerve fibers could be ignored, because the electrical activities were TTX resistant. When the external $\mathrm{Na}$ concentration was reduced from 137.4 to $16.7 \mathrm{~mm}$, the membrane potential increased (hyperpolarization) transiently, and then returned to a level slightly depolarized, compared to that of $137.4 \mathrm{~mm}-\mathrm{Na}$. The mean amplitude of the depolarization was $3.8 \pm 1.7 \mathrm{mV}(n=7)$ which was measured after the membrane potential became stable. With brief electrical stimulation applied during the transient hyperpolarization, the spike potential followed by the slow potential with a high amplitude was induced (Fig. 6A). As the membrane 


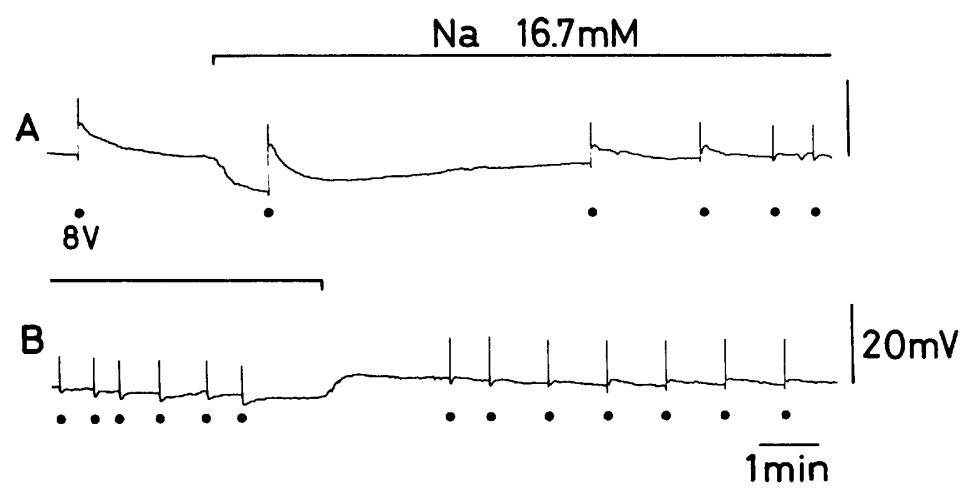

Fig. 6. Effects of $\mathrm{Na}$ deficiency on the electrical activities. $\mathrm{B}$ is the successive recording after $\mathrm{A}$. Na was reduced from 137.4 to $16.7 \mathrm{~mm}$ during the period indicated above the traces. All electrical stimulations were of $8 \mathrm{~V}$ in intensity.

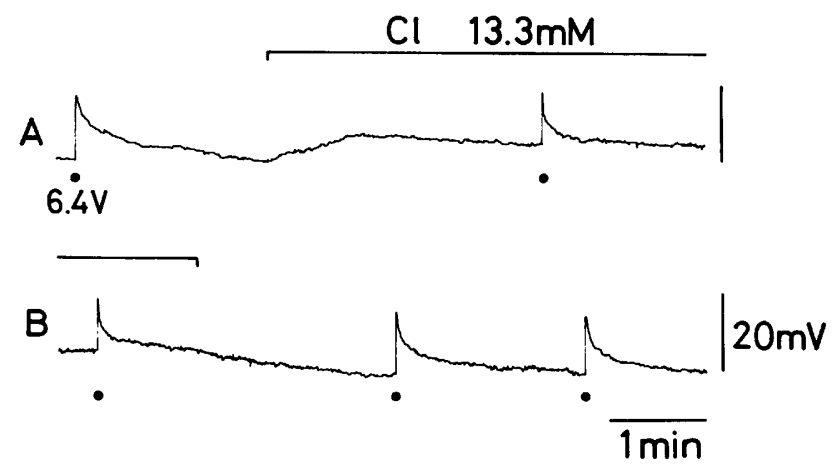

Fig. 7. Effects of $\mathrm{Cl}$ deficiency on the electrical activities. $\mathrm{B}$ is the successive recording after $\mathrm{A}$. $\mathrm{Cl}$ was reduced from 134.0 to $13.3 \mathrm{~mm}$ during the period indicated above the traces. All electrical stimulations were of $6.4 \mathrm{~V}$ in intensity.

depolarized, however, the amplitude of both the spike potential and the slow potential decreased gradually, and the latter became a hyperpolarizing potential (Fig. 6B). Upon re-introduction of the $137.4 \mathrm{~mm}-\mathrm{Na}$ solution, the membrane depolarized transiently and then gradually repolarized. During this procedure, the amplitude of the spike potential increased and the depolarizing slow-potential was restored, although the amplitude was not as large as that of the control.

\section{Effects of $\mathrm{Cl}$ deficiency on the electrical activities}

To examine the possible involvement of $\mathrm{Cl}$ in the slow potential, effects of $\mathrm{Cl}$ deficiency on electrical activities were investigated (Fig. 7). When the external $\mathrm{Cl}$ concentration was reduced from 134.0 to $13.3 \mathrm{~mm}$, the membrane depolarized. The mean amplitude of the depolarization was $7.4 \pm 4.3 \mathrm{mV}(n=11)$ when measured 


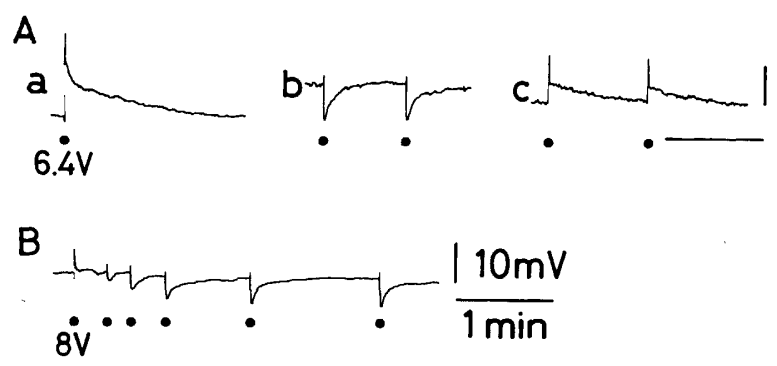

Fig. 8. Effects of Ca-rich solution on electrical activities. A: a, electrical activity in $2.5 \mathrm{~mm}$-Ca solution; $\mathrm{b}$, electrical activities after exposure to $20 \mathrm{~mm}-\mathrm{Ca}$ solution for $15 \mathrm{~min}$; c, electrical activities $5 \mathrm{~min}$ after re-introduction of $2.5 \mathrm{~mm}$-Ca solution. All electrical stimulations were of $6.4 \mathrm{~V}$ in intensity. B: electrical activities after exposure to $20 \mathrm{~mm}$-Ca solution for $18 \mathrm{~min}$. The stimulation farthest to the left in this recording was the first one applied to this portion since the $\mathrm{Ca}$ concentration was raised. All electrical stimultations were of $8 \mathrm{~V}$ in intensity. $\mathrm{A}$ and $\mathrm{B}$ are the recordings from the different preparations.

after the membrane potential became stable. In this solution, the depolarizing slowpotential was induced, but there was some reduction in amplitude (Fig. 7A). The membrane repolarized and the amplitude of the slow potential increased after reintroduction of the $134.0 \mathrm{~mm}-\mathrm{Cl}$ solution (Fig. 7B).

\section{Effects of Ca-rich solution on the electrical activities}

The experiment using $\mathrm{Ca}$-deficient or Ca-free solution was difficult to analyze, because both pre- and postjunctional processes had to be considered. Therefore, the effects of the Ca-rich solution on the electrical activities were investigated to examine the possible involvement of $\mathrm{Ca}$, although some modulation in the prejunctional process was inevitable (Fig. 8). If the spike potential and following slow potential were produced by the inward Ca-current, the amplitude would be expected to increase in the Ca-rich solution. The brief electrical stimulation, however, produced rather unexpected membrane activities in the $20 \mathrm{~mm}-\mathrm{Ca}$ solution. In this experiments, a Tris-buffered solution was used as the standard solution to prevent the precipitation of $\mathrm{Ca}$. The resting membrane potential in this solution was $-52.9 \pm 3.3 \mathrm{~mm}(n=45)$. When the external Ca concentration was increased from 2.5 to $20 \mathrm{~mm}$, the membrane depolarized. The mean amplitude of the depolarization was $6.7 \pm 1.2 \mathrm{mV}(n=11)$ when measured after the membrane potential became stable. In a Ca-rich solution, brief electrical stimulation produced neither spike potential nor depolarizing slow-potential but rather a hyperpolarizing slow-potential (Fig. 8A, b). The small positive deflections observed in this Figure were not the spike potentials but rather artifacts of the stimulation. These hyperpolarizing slow-potentials persisted in the presence of TTX $\left(10^{-6} \mathrm{M}\right)$ or atropine $\left(10^{-5} \mathrm{M}\right)$. The spike potentials and the depolarizing slow-potentials were recovered after re-introduction of the $2.5 \mathrm{~mm}-\mathrm{Ca}$ solution (Fgi. $8 \mathrm{~A}, \mathrm{c}$ ). 
In a Ca-rich solution, a phenomenon such as that shown in Fig. 8B was frequently observed. The first stimulation applied in the $20 \mathrm{~mm}-\mathrm{Ca}$ solution produced a small spike potential and a small depolarizing slow-potential. With the second stimulation, these potentials were no longer produced and the small hyperpolarizing slow-potential appeared. The amplitude of the hyperpolarizing slow-potential increased gradually as the stimulations were repeated, reaching some $10 \mathrm{mV}$. The explanation that this change in the membrane responses depended on exposure time to the Ca-rich solution does not seem to be tenable, because after recording the hyperpolarizing slow-potential from a portion of the specimen, the same sequence of change was observed at different portions of the same specimen. The stimulated portion from the point-stimulating method was limited to the surrounding area of the anodal stimulating electrode, and a major part of the specimen remained unstimulated.

We also observed the electrical activities in a $10 \mathrm{~mm}-\mathrm{Ca}$ solution (not shown in the figure). These were qualitatively identical to those in the $20 \mathrm{~mm}$-Ca solution, i.e., the amplitude of the slow potential decreased and hyperpolarizing slow-potentials were sometimes induced.

\section{DISCUSSION}

In various vascular and visceral smooth muscle preparations, an electrical current of short duration has been used to stimulate nerve fibers, and sensitivity to TTX has been considered proof of neurogenic responses. Considering the all-ornone nature of the action potntial generation, concentrations of TTX (over $10^{-7} \mathrm{M}$ ) seem to completely suppress the action potential generation in the nerve fibers. The e.j.p.s, however, were still evoke by the perivascular nerve stimulation in the presence of TTX in the guinea-pig's ear artery, although increased stimulus intensity was required (KEEF and NEILS, 1982). This observation suggests that a part of the transmitter release occurs without generation of the action potential. As suggested in case of the neuromuscular junction (KATZ and MiLEDI, 1967), the transmitter is released in the presence of TTX as long as the presynaptic membrane is depolarised, thus allowing the external $\mathrm{Ca}$ to enter the cell. In the present experiment, we used a single brief current $0.05 \mathrm{~ms}$ in duration, the objective being to stimulate perivascular nerves without any direct effect to the smooth muscle cells. Outward current injected into the smooth muscle cell produced the spike potential but not the depolarizing slow-potential. Brief electrical stimulation failed to evoke the spike potential in the $20 \mathrm{~mm}$-Ca solution, where the driving force for inward Cacurrent possibly generating the spike potential was enhanced. From these observations, the brief electrical stimulation used in this experiment was considered to have no direct effect on the smooth muscle cells. As TTX, guanethidine and atropine had no effect on the electrical responses, a brief stimulation might evoke these responses mainly by depolarizing the varicosities of the nonadrenergic, noncholinergic nerves, thus allowing the transmitter to be released. Or, alter- 
natively, other non-neural cells might be stimulated and release some vasoactive substance producing the electrical activities. The released transmitter or vasoactive substance was not determined.

In the guinea-pig basilar artery, KARASHIMA and KURIYAMA (1981) found that a single stimulus $0.2 \mathrm{~ms}$ in duration evoked only an e.j.p. of a very small amplitude, and that an action potential was induced only by repetitive stimulation of high frequency and only in the presence of TEA. In the present study, however, a single stimulus $0.05 \mathrm{~ms}$ in duration produced the spike potential followed by the slowlydelining depolarization, not only in the artery of the circle of Willis but also in the basilar artery. A possible cause of the difference between these two results may be some difference in efficacy of the stimulation due to arrangement of the stimulating electrodes, because we failed to induce large electrical activities using electrodes of the partition-stimulating method, also used by KARASHIMA and KURIYAMA (1981). Using a pair of fine platinum wires as the stimulating electrodes and placing them on both sides of the rat basilar artery, HiRST et al. (1982) observed the action potential followed by depolarization lasting up to $2 \mathrm{~min}$ induced by a single brief stimulation $(0.05-0.1 \mathrm{~ms})$.

In the rat portal vein, the equilibrium potentials of $\mathrm{Na}$ and $\mathrm{Cl}$ are positive while that of $\mathrm{K}$ is negative in respect to the resting membrane potential (WAHLSTRÖM, 1973). If this is applicable to the guinea-pig's cerebral artery, an increase of $\mathrm{Na}$ or $\mathrm{Cl}$ conductance of the membrane and a decrease of $\mathrm{K}$ conductance would depolarize the membrane. Increase of Ca conductance is also a possible cause of membrane depolarization, because its equilibrium potential is positive.

The involvement of membrane $\mathrm{K}$ conductance in the slow potential was likely minor, because the slow potential was not affected by the presence of TEA. When the external $\mathrm{Na}$ was reduced, the membrane hyperpolarized transiently indicating that the electro-chemical gradient for $\mathrm{Na}$ across the membrane was reversed. This hyperpolarization was also observed in the cerebral artery of a dog (FUJIWARA et al., 1982) and in the guinea-pig's basilar artery (FujIWARA and KuRIYAMA, 1983). During this period, the membrane would be hyperpolarized to a greater extent (hyperpolarizing slow-potential) if the membrane conductance for $\mathrm{Na}$ was increased by the electrical stimulation. However, the depolarizing slow-potential was evoked in the hyperpolarized membrane. After this hyperpolarizing period, the membrane depolarized, thereby suggesting a completion of the re-distribution of $\mathrm{Na}$ across the membrane. When the external $\mathrm{Cl}$ was reduced, the membrane depolarized, indicating that the equilibrium potential of $\mathrm{Cl}$ shifted to a more positive value. This depolarization was also observed in the dog's cerebral artery (FuJiwara et al., 1982). During this period, the depolarizing slow-potential would be potentiated if it were produced by an increased $\mathrm{Cl}$ conductance of the membrane. However, the amplitude of the slow potential decreased during this period. The process of $\mathrm{Cl}$ redistribution seemed to be slower than that of $\mathrm{Na}$, because the membrane remained depolarized for several minutes during which the $\mathrm{Cl}$-deficient solution was applied. The involvement of the membrane conductances for $\mathrm{Na}$ and $\mathrm{Cl}$ on the depolarizing 
slow-potential is probably not a major one.

After re-distribution of $\mathrm{Na}$ was completed in the $\mathrm{Na}$-deficient solution, the spike potentials were followed not by depolarizing but rather by hyperpolarizing slow-potentials. The hyperpolarizing slow-potentials were also observed in the Carich solution, although they were not preceded by the spike potentials. Here, at least two factors have to be considered: (i) the equilibrium potential of the slow potential shifts to a more negative value and reverses the polarity of the slow potential, or (ii) the small hyperpolarizing slow-potential is superimposed on the large depolarizing one in the control condition and is visualized when the depolarizing one is inhibited. There are several observations which favor explanation (ii). The hyperpolarizing slow-potential appeared and the amplitude increased gradually as the stimulations were repeated in the $\mathrm{Ca}$-rich solution. This may suggest that the release of a transmitter or of a substance which generates the depolarizing slow-potential is gradually inhibited by repeated stimulations in the Ca-rich solution and by unmasking the hyperpolarizing slow-potential. In a dog's saphenous vein, HEYNDRICKX and VANHOUTTE (1971) observed that when the external Ca concentration was raised to $14.4 \mathrm{~mm}$, the contractile response to nerve stimulation decreased while that to exogeneous norepinephrine increased. This suggests that the release of norepinephrine from the nerve varicosities is inhibited in the Ca-rich solution. This may also be the case in the releasing process of a substance which generates the depolarizing slow-potential in the guinea-pig's cerebral artery, although the substance is not likely to be norepinephrine. In a dog's middle cerebral arrery, SUZUKI and FUJIWARA (1982) observed the hyperpolarizing slow-potential preceded by e.j.p. in a solution with a normal Ca-concentration, thereby suggesting the existence of some inhibitory innervation. The hyperpolarizing slow-potential seems to be different in origin from the depolarizing one, although explanation (i) cannot be ruled out completely. As with case of the dog's cerebral artery, the guinea-pig's cerebral artery may also have a functioning inhibitory innervation.

The involvement of the membrane conductance for $\mathrm{Ca}$ in the depolarizing slow-potential, thus, could not be examined. Although the slowly-declining contraction produced by the brief stimulation might be explained if the depolarizing slow-potential is generated by an inward Ca-current, further study must be done. Is the depolarizing slow-potential specific for the cerebral artery, as suggested by HiRs et al. (1982)? In the guinea-pig's mesenteric artery, using the same stimulating electrodes used in the present experiment, a single breif stimulation $0.05 \mathrm{~ms}$ in duration induced the depolarizing slow-potential with the same configuration as that in the cerebral artery, although a higher voltage was required (Y. Yamamoto, unpublished observation). BELL (1969) also observed a slowly-declining depolarization induced by repetitive stimulation in the guinea-pig's uterine artery. The mechanism generating the depolarizing slow-potential may be inherent in the arterial tissue, as well as the cerebral artery, and it may easily be triggered by weak stimulation. 
This study was supported in part by a Grant-in-Aid for Scientific Research from the Ministry of Education, Science and Culture of Japan.

\section{REFERENCES}

Aвe, Y. and Tomita, T. (1968) Cable properties of smooth muscle. J. Physiol. (Lond.), 196: $87-100$.

BELL, C. (1969) Transmission from vasoconstrictor and vasodilator nerves to single smooth muscle cells of the guinea-pig uterine artery. J. Physiol. (Lond.), 205: 695-708.

Edvinsson, L. and MackenziE, E. T. (1976) Amine mechanisms in the cerebral circulation. Pharmacol. Rev., 28: 275-348.

Fujiwara, S., Itoh, T., and Suzuki, H. (1982) Membrane properties and excitatory neuromuscular transmission in the smooth muscle of dog cerebral arteries. $B r . J$. Pharmacol., 77: 197-208.

Fujiwara, S. and Kuriyama, H. (1983) Effects of agents that modulate potassium permeability on smooth muscle cells of the guinea-pig basilar artery. Br. J. Pharmacol., 79: $23-35$.

HARDER, D. D. and SPERELAKIS, N. (1979) Action potentials induced in guinea pig arterial smooth muscle by tetraethylammonium. Am. J. Physiol., 237: c75-c80.

Heistad, D. D. and MarCus, M. L. (1978) Evidence that neural mechanisms do not have important effects on cerebral blood flow. Circ. Res., 42: 295-302.

HeyndRickx, G. and Vanhoutte, P. (1971) Variations in external calcium concentration and sensitivity of venous smooth muscle to temperature changes. Arch. Int. Physiol. Biochim., 79: 169-173.

Hirst, G. D. S., Neild, T. O., and SilverberG, G. D. (1982) Noradrenaline receptors on the rat basilar artery. J. Physiol. (Lond.), 328: 351-360.

Imaizumi, Y. and WatanaBe, M. (1981) The effect of tetraethylammonium chloride on potassium permeability in the smooth muscle cell membrane of canine trachea. $J$. Physiol. (Lond.), 316: 33-46.

Karashima, T. and Kuriyama, H. (1981) Electrical properties of smooth muscle cell membrane and neuromuscular transmission in the guinea-pig basilar artery. Br. J. Pharmacol., 74: 495-504.

Katz, B. and Miledi, R. (1967) Tetrodotoxin and neutromuscular transmission. Proc. $R$. Soc. Lond. (Biol.), 167: 8-22.

KeEF, K. and NeILD, T. O. (1982) Modification of the response to nerve stimulation in small arteries of guinea-pig caused by distension of the artery. J. Physiol. (Lond.), 331: 355365 .

Paton, W. D. M. (1975) Transmural and field stimulation of nerve-smooth muscle preparations. In: Methods in Pharmacology, ed. by Daniel, E. E. and Paton, D. M., Plenum Press, New York, and London, Vol. 3, pp. 313-320.

Purves, M. J. (1978) Do vasomotor nerves significantly regulate cerebral blood flow? Circ. Res., 43: 485-493.

Suzuki, H. and Fumiwara, S. (1982) Neurogenic electrical responses of single smooth muscle cells of the dog middle cerebral artery. Circ. Res., 51: 751-759.

W AHLSTRÖM, B. A. (1973) Ionic fluxes in the rat portal vein and the applicability of the Goldman equation in predicting the membrane potential from flux data. Acta Physiol. Scand., 89: 436-448. 